\title{
Problematizando a atenção em HIV-Aids na Estratégia Saúde da Família
}

Problematizing health care in HIV-AIDS in Family Health Strategy

Problematizando la atención sobre el VIH-SIDA en la Estrategia Salud de Família

\section{Gustavo Zambenedetti}

Universidade Federal do Rio Grande do Sul, Porto Alegre, Rs, Brasil

Nalu Silvana Both

Universidade Federal do Rio Grande do Sul, Porto Alegre, Rs, Brasil.

\begin{abstract}
Resumo
O objetivo da pesquisa foi problematizar a atenção em HIV-Aids na Estratégia Saúde da Família - ESF. Realizamos um estudo qualitativo, com duas equipes da ESF que compõem uma unidade de saúde em Porto Alegre-RS. Foram realizadas entrevistas com os enfermeiros, médicos e técnicos de enfermagem e um grupo focal com os Agentes Comunitários de Saúde. A análise evidencia que, apesar das políticas públicas enfatizarem o estabelecimento de ações pautadas pela noção de vulnerabilidade, a noção de grupos de risco ainda permanece muito presente no contexto em análise. Apontamos o desafio de que a descentralização de ações em HIV-Aids para a Estratégia Saúde da Família seja acompanhada por processos de qualificação da atenção em saúde, baseadas na integralidade e co-responsabilização das ações.
\end{abstract}

Palavras-chave: Aids; HIV; Estratégia Saúde da Família; vulnerabilidade; prevenção.

\begin{abstract}
The objective of this research was to problematize health care in HIV-AIDS in the Family Health Strategy - FHS. We conducted a qualitative study, with two teams that make FHS a health unit in Porto Alegre-RS. Interviews were conducted with nurses, doctors and nursing staff and a focus group with the Community Health Agents. The analysis shows that, despite public policies emphasizing the establishment of actions guided by the notion of vulnerability, the notion of risk group still shown in this very context analysis. We point out the challenge of decentralization to development of HIV-Aids for the Family Health Strategy is accompanied by qualification processes of health care, based on integrality and coresponsability of shares.
\end{abstract}

Key Words: Aids; HIV; family health strategy; Vulnerability; prevention. 


\section{Resumen}

El objetivo de esta investigación fue problematizar la atención sobre el VIH-SIDA en la Estrategia de Salud de la Familia - ESF. Se realizó un estudio cualitativo, con dos equipos de la ESF que componen una unidad de salud de Porto Alegre-RS. Se realizaron entrevistas con enfermeras, médicos y auxiliares de enfermería y un grupo focal con los Agentes Comunitarios de Salud. El análisis muestra que, a pesar de las políticas públicas enfatizando el establecimiento de acciones guiadas por la noción de vulnerabilidad, la noción de grupo de riesgo aún se muestra mucho presente en contexto del análisis. Se señala el desafío de la descentralización para el desarrollo del VIH-SIDA de la Estrategia Salud de la Familia se acompaña de procesos de cualificación de la atención de la salud, basados en la integralidad y co-responsabilidad de las acciones.

Palavras clave: SIDA; HIV; Estrategia Salud de la Familia; vulnerabilidad; prevención.

A Estratégia Saúde da Família-ESF é uma das estratégias do Ministério da Saúde para reorganizar o sistema de saúde brasileiro. Surge em âmbito nacional em 1994, sendo denominada Programa Saúde da Família (PSF). Em 2006, com a portaria $\mathrm{n}^{\circ} 648$ (Brasil, 2006a), passa a se chamar Estratégia Saúde da Família (ESF), visando ressaltar seu caráter de estratégia de reorganização do sistema de saúde.

A inserção de ações relacionadas ao HIV-Aids na atenção básica passou a ocorrer em meados da década de 1990, intensificando-se nos anos 2000. Alguns aspectos justificaram esta inserção, como a constatação realizada pelo Ministério da Saúde, em 1998, de que o diagnóstico ocorria tardiamente no Brasil - ou seja, quando o sistema imunológico já estava debilitado - demandando novas estratégias para universalização do acesso ao diagnóstico e prevenção (Brasil, 2008). Além disso, houve a redução do preconceito e estigma, facilitando o acesso e aceitação da doença (Brasil, 2008). Na passagem dos anos 1990 para 2000 também ocorreu uma mudança no perfil da epidemia, que passou a ser caracterizada pelas tendências de feminilização, heterossexualização, pauperização, interiorização e juvenização (Brasil, 2006b), demandando a expansão do acesso à prevenção para diferentes públicos. Ao mesmo tempo em que novas demandas surgiam em relação à Aids, a ESF expandia-se e consolidava-se no Brasil, constituindo-se como um ponto de atenção 
estratégico para ações relacionadas ao HIV-Aids.

Nos anos 2000 ocorre a publicação de manuais apontando diretrizes sobre a assistência em HIV-Aids e outras DST na atenção básica (Brasil, 2003; 2005; 2006b). A ênfase recai sobre a atividade de aconselhamento, definida como "um diálogo baseado em uma relação de confiança que visa proporcionar à pessoa condições para que avalie seus próprios riscos, tome decisões e encontre maneiras realistas de enfrentar seus problemas relacionados às DST/HIV/Aids" (Brasil, 2003, p.9). São propostas ações de prevenção às DST/HIV/Aids dentro das unidades de saúde, como o acolhimento, a educação em saúde em sala de espera, o diagnóstico e aconselhamento, a disponibilização de insumos de prevenção e a comunicação dos parceiros sexuais. Também são propostas ações de prevenção envolvendo a comunidade, como mapeamento de grupos mais vulneráveis, encaminhamento para unidade de saúde ou outros serviços de referência, acesso à informação, além de ações que auxiliem no combate ao preconceito e discriminação relacionados à sexualidade, ao uso de drogas, entre outros (2005, 2006b). É preconizada, ainda, a atuação de forma integrada com os profissionais dos serviços de referência: os Centros de Testagem e
Aconselhamento - CTA e os Ambulatórios ou Serviços de Atenção Especializada SAE.

As pesquisas que abordam a interface da atenção em HIV-Aids com a atenção básica têm ressaltado diferentes aspectos. Silva et al (2005) focalizam a questão da integralidade da atenção, ressaltando que a rede assistencial encontra-se desarticulada e fragmentada. Seoane e Fortes (2009) e Abdala e Nichiata (2008) abordam a dimensão do sigilo/privacidade e confidencialidade do diagnóstico, considerando-se as especificidades do HIV. Já Ferreira e Nichiata (2008) e Sousa, Santo e Motta (2008) destacam o atravessamento de gênero e vulnerabilidade na atenção em HIV-Aids na ESF.

Nosso artigo propõe uma problematização sobre o modo como as equipes de ESF planejam e executam ações no campo da atenção em HIV-Aids. Estabelecemos como ponto de partida a pergunta: "Como ocorre a atenção em HIV-Aids em uma unidade de Saúde da Família no município de Porto AlegreRS?”. A partir da perspectiva da integralidade em saúde, propomos pensar a “atenção" como um conjunto de ações que podem envolver promoção e prevenção, tratamento e reabilitação. Nesse sentido, 
nos interessa investigar, no âmbito da atenção em HIV-Aids:

- que ações são incorporadas pelas equipes de ESF e quais são designadas para outros serviços e níveis assistenciais.

- em relação às ações desenvolvidas na ESF, como elas ocorrem.

Ao delimitarmos tal pergunta e objetivos, torna-se importante apontar a compreensão da Aids não apenas como um evento viral, de cunho biomédico. Mas sim, como um fenômeno social complexo, evidenciando a articulação biológico-social (Herzlich, Pierret, 2005). A descoberta da Aids no início da década de 1980 trouxe à tona discussões sobre como a sociedade se relaciona com temas considerados tabus: doença, morte, sexualidade, (in)fidelidade, uso de drogas, religiosidade, relações de poder e gênero. Trouxe desafios às equipes de saúde: como abordar temas considerados tabus? Como operar a atenção em saúde sob o eixo da integralidade, considerando-se os impactos da Aids nas diversas dimensões da vida biológica, social, psicológica?

Ao longo da epidemia, três conceitos ganharam destaque e foram utilizados para instrumentalizar as práticas preventivas de resposta à Aids: grupos de risco, comportamento de risco e vulnerabilidade (Ayres e col, 2009a, 2009b; Paiva, 2000). Tais noções estabelecem diferentes modos de configurar a Aids como problema de saúde, modulando o olhar e a intervenção dos profissionais. Ao perguntarmos "como ocorrem as ações no campo de atenção em HIV-Aids", buscamos caracterizar o modo como os profissionais da ESF descrevem suas ações, analisando que noções instrumentalizam seu trabalho e o quanto tais noções aproximam a Aids de uma compreensão apenas biomédica ou como fenômeno social complexo. Compreendemos que estas diferentes compreensões são expressões da dicotomia entre saúde pública e saúde coletiva. Segundo Birman (2005), o ponto de emergência da noção de saúde coletiva corresponde à incorporação das contribuições das ciências sociais e humanas ao campo da saúde, interrogando o naturalismo médico e medicalizante do espaço social que predominava na chamada saúde pública.

\footnotetext{
a caução científica do discurso naturalista da medicina sempre colocou entre parênteses a dimensão política das práticas sanitárias. A recente epidemia de AIDS revela mais uma vez esse processo, que se repete desde o século XIX no Ocidente: em nome do discurso da ciência, legitimam-se práticas de marginalização de diferentes segmentos sociais (Birman, 2005, p. 12).
} 
Nesta perspectiva, a saúde coletiva representa uma ampliação e redefinição do campo da saúde, pois se constitui a partir da crítica sistemática ao universalismo naturalista do saber médico. Apesar de levar em consideração as explicações biomédicas e epidemiológicas, não as considera suficientes para a resolução de problemas considerados complexos, que exigem a conjugação de outros saberes, visando produzir conhecimentos não apenas sobre a universalidade e naturalidade dos fenômenos, mas sobre as suas singularidades e simbolismos, constituídos em contextos sociais e históricos.

A noção de grupos de risco, desenvolvida no campo da epidemiologia, tende a reduzir a Aids a um fenômeno viral, biológico. Tal noção foi largamente utilizada no início da epidemia, respondendo a tentativa de identificar quem eram as pessoas que estavam adoecendo e quais as suas características, “o que levou já em 1982 à descrição pelo Centro de Controle de Doenças (CDC) dos Estados Unidos de quatro grupos de risco: homossexuais, hemofílicos, haitiano e usuários de heroína" (Ayres e col, 2009b, p. 392). De acordo com a racionalidade epidemiológica, as pessoas pertencentes a tais grupos teriam maior probabilidade de serem atingidas pela Aids. Porém, conforme Herzlich e Pierret (2005), o fenômeno social Aids é constituído por interferências e retroações entre conhecimento científico e conhecimento comum. Nesse movimento de interferências e retroações, os conceitos e critérios epidemiológicos mesclaram-se com a moral pública, associando alguns dos grupos de risco citados às representações de pecado, desvio, excesso moral, promiscuidade. Os hemofílicos, por outro lado, eram vistos como vítimas, assim como as mulheres e as crianças (Seffner, 1998). A partir da reivindicação de organizações da sociedade civil e com base nos dados que mostravam o aumento da infecção pelo HIV em indivíduos "fora" dos chamados grupos de risco, emergiu uma segunda noção para instrumentalizar a atenção em HIV-Aids, denominada "comportamento de risco" (Ayres e col, 2009b). Essa concepção deslocou o foco do "tipo" de pessoa ou grupo para as práticas e comportamentos individuais que podem colocar alguém em risco para a infecção pelo HIV, explicitando a Aids como problema de qualquer pessoa. Porém, tornou-se uma concepção culpabilizante e homogeneizante, pois ignorou o impacto das diferenças de renda, cor, classe social e outros fatores na constituição do risco para a transmissão do HIV. 
Já a concepção de vulnerabilidade incorpora as discussões do campo das ciências sociais e humanas, partindo de uma compreensão da Aids como fenômeno social complexo, perpassado por múltiplas possibilidades de significação. Enquanto a noção de risco busca excluir a variabilidade dos fenômenos, evidenciando padrões, probabilidades e repetições, o referencial da vulnerabilidade busca justamente o contrário: ressaltar as múltiplas possibilidades de relação e variação em um fenômeno, os significados sociais e culturais, etc. (Ayres e col., 2009a).

É necessário enfatizar que, apesar de terem sua emergência em pontos cronológicos distintos, conformando uma aparente linearidade e sucessividade, no cotidiano essas diferentes noções podem co-existir e se sobrepor, sendo incorporadas às ações dos profissionais em saúde. Ayres e col (2009b) afirmam que as análises de vulnerabilidade não prescindem das análises de risco, desde que o risco não seja compreendido como ente abstrato, e possa ser colocado em correlação com diversos fatores e significados sociais e culturais.
Método

Utilizamos a abordagem qualitativa, inserida na perspectiva da pesquisa social em saúde. Minayo (1992) compreende a atividade de pesquisa como a atividade básica da ciência na sua indagação e descoberta da realidade. A peculiaridade da pesquisa social é levar em consideração a carga histórica, refletindo posições frente à realidade, dinâmica social, preocupações e interesses de grupos determinados. A pesquisa qualitativa preocupa-se em apreender a percepção dos sujeitos envolvidos em um fenômeno social que se desenvolve em um determinado contexto.

Os sujeitos da pesquisa foram constituídos pelos integrantes de duas equipes de ESF de uma unidade de saúde do município de Porto Alegre: 2 médicos, 2 enfermeiros, 4 técnicos de enfermagem e 7 Agentes Comunitários de Saúde-ACS.

A escolha da equipe levou em consideração dois aspectos. Em primeiro lugar, o pertencimento da unidade à gerência distrital Partenon-Lomba do Pinheiro, que apresenta a maior incidência de Aids no município de Porto Alegre (SMS-POA, 2008). Em segundo lugar, a disponibilidade e desejo da equipe para participar da pesquisa. A partir disso estabeleceu-se contato com a Gerência 
Distrital e com uma unidade de ESF, que autorizaram a realização da pesquisa.

Os dados foram produzidos em julho de 2009. Como técnicas de coleta utilizamos entrevistas semi-estruturadas e grupo focal. As entrevistas foram realizadas individualmente com os médicos, enfermeiros e técnicos de enfermagem. O grupo focal foi realizado com os ACS. As entrevistas e o grupo focal foram gravados e posteriormente transcritos.

Esta pesquisa seguiu as diretrizes e normas regulamentadas pela resolução $n^{\circ}$ 196/96. Após o término da pesquisa houve uma reunião com as equipes de ESF para a apresentação dos resultados.

A análise foi realizada em duas etapas, segundo proposto por Gomes (2007). A primeira correspondeu ao processo de seleção e organização dos dados, realizada através de uma leitura do conjunto do material, de forma compreensiva. A segunda etapa correspondeu à exploração do material e análise, tendo como referência os objetivos propostos e o referencial analítico.

A noção de problematização permite interrogar os significados expressos pelos sujeitos a determinado fenômeno, desnaturalizando e demonstrando suas contingências sociais e históricas. Segundo Revel (2005), o termo problematização implica em duas conseqüências. Primeiramente, na consideração de que o exercício crítico se opõe à idéia de uma busca metódica de solução, aproximando-se da proposição de instauração de uma distância crítica, que possibilita pensar de outro modo, deslocar. Em seguida, na consideração de que a problematização não implica em um relativismo, mas na análise das relações historicamente estabelecidas com a verdade. Afirmamos a possibilidade de aliar esta ferramenta conceitual à abordagem qualitativa, considerando-se a compreensão da saúde coletiva como um campo que visa conjugar diferentes saberes para a compreensão de problemas considerados em sua complexidade.

As noções de problema social complexo (Herzlich e Pierret, 2005) e vulnerabilidade (Ayres e col, 2009) constituem-se também como importantes operadores conceituais, atuando como ferramentas de desnaturalização. A emergência histórica destes conceitos visou romper, respectivamente, com a noção de grupo de risco e com a compreensão da Aids como mero fenômeno viral de ordem biomédica, noções hegemônicas no campo da saúde, especialmente na abordagem da Aids. Elas permitem interrogar enunciados presentes nas falas dos participantes da pesquisa, 
abrindo possibilidades para pensar diferentes formas de abordagem do fenômeno Aids - e não uma única forma. A desnaturalização constitui-se justamente nesse movimento de tomar um conceito em sua forma instituída e demonstrar que ele não existe desde sempre. Nessa perspectiva, desnaturalizar é também deslocar, possibilitar ver o fenômeno de outras maneiras, constituindo-se ai o exercício analítico.

Apresentaremos a caracterização das ações e, em seguida, faremos a discussão dos resultados, propondo uma problematização sobre o modo como determinadas noções permeiam a intervenção dos profissionais das equipes de ESF.

Com a finalidade de preservar o anonimato das informações, os recortes de falas dos participantes serão identificados por números (prof. 1 e assim sucessivamente).

\section{Resultados :}

\section{Planejamento de ações}

Apesar de ser preconizada no âmbito da política de saúde e da ESF (Brasil, 2006b), a vigilância epidemiológica em relação aos casos de Aids não é utilizada como ferramenta para o planejamento das ações pelas equipes investigadas. Durante a apresentação do projeto de pesquisa às equipes houve reações de surpresa em relação aos dados epidemiológicos da Aids no estado, município e gerência distrital desconhecidos até então. A maioria dos profissionais não sabe quantas pessoas da área adscrita à unidade estão infectadas pelo HIV, a não ser os ACS, que relataram conhecer, em média, duas a quatro pessoas infectadas pelo HIV por micro-área. Tal dado chama a atenção pelo fato de Porto Alegre figurar como o município com maior incidência de Aids no Brasil (Brasil, 2012). A gerência distrital da qual a unidade pesquisada faz parte teve incidência, em $2006^{\mathrm{II}}$, de 110,2 casos de Aids para cada 100.000 habitantes (SMSPOA, 2008), levando-se em consideração apenas os dados notificados no SINAN ${ }^{\text {III }}$. Neste mesmo ano, a incidência no município de Porto era de 78,5 casos para cada 100.000 hab, e a média nacional era de menos de 20 casos em 100.000hab.

Os profissionais relatam ausência de capacitação ou processos de educação em saúde visando à abordagem do tema HIV-Aids. Apenas um profissional relatou ter participado de um congresso na área de DST-Aids em 2008. Os ACS referiram que quando surgem dúvidas sobre o tema, procuram auxílio de outros profissionais da 
equipe ou fazem buscas de conteúdos relacionados à área na internet.

Esses dados apontam que, apesar da magnitude epidemiológica da Aids em Porto Alegre, a ESF não é vista como dispositivo estratégico na atenção em HIVAids no âmbito municipal. A ESF é guiada por prioridades delimitadas na política de atenção básica (Brasil, 2006). Apesar da Aids não ser uma das prioridades elencadas em nível nacional, a política de atenção básica ressalta que problemas característicos de localidades específicas podem ser incorporados como prioridade pelo nível local. No entanto, a equipe tem como foco apenas as prioridades elencadas na política nacional de atenção básica. Feuerweker (2005) ressalta o desafio que constitui a flexibilização do processo de trabalho da ESF para incorporação de outras demandas que extrapolem as prioridades delimitadas nacionalmente, visando responder ao nível local.

\section{Ações realizadas no contexto da ESF}

As ações realizadas pela equipe relacionam-se com orientações de prevenção e solicitação do teste anti-HIV. $\mathrm{O}$ acompanhamento das pessoas vivendo com HIV-Aids é compreendido como responsabilidade dos serviços especializados. Nesse sentido, adesão, repercussão psicológica e social do diagnóstico e solicitação de exames são vistos como competências dos serviços especializados, sendo a ESF responsável por um "cuidado geral" dessas pessoas.

\section{Solicitação do exame anti-HIV}

Segundo os relatos obtidos, os motivos que disparam a solicitação do exame anti-HIV se relacionam principalmente com três situações:

1) No pré-natal, em decorrência de um protocolo que indica a solicitação do exame no primeiro e terceiro trimestres gestacionais;

2) Demanda do paciente;

3) Percepção dos profissionais acerca de sinais clínicos e sintomas sugestivos de Aids ou do histórico de comportamentos considerados "de risco" pelos profissionais.

Os profissionais relataram orientar o paciente durante a solicitação do teste anti-HIV, abordando o que é o exame e reforçando a necessidade de retornar com o resultado, tal como preconizado em Brasil (2005, 2003): “a gente orienta como se proteger, conversa com a pessoa, vê por que ela acha que tem algum risco, pra gente tentar minimizar aquele risco ali. Então sempre tem uma conversa e a gente pede o exame (prof.2)". Porém, poucos 
usuários retornam com o resultado, possivelmente em função do modo como o fluxo de testagem é estabelecido (aspecto que será retomado no decorrer do artigo). A principal situação de solicitação mencionada foi no pré-natal. Porém, nesta situação, nem sempre a abordagem preventiva em relação ao HIV e outras DST é a mesma: "Não se faz a mesma abordagem, por exemplo, de outro paciente que vem por outra causa, por outra queixa. A gente simplesmente diz 'olha, é importante, faz parte da rotina do prénatal', a gente não tem a mesma preocupação" (prof.1).

Os profissionais relataram que a solicitação do teste anti-HIV também pode ocorrer em função de sinais clínicos e do histórico do usuário. Também foram relatadas situações onde o usuário solicita o teste anti-HIV durante as consultas médicas, algumas vezes de maneira explícita e outras de maneira implícita, como aponta a fala seguinte:

Tem o paciente que vem e pede (o teste anti-HIV) por ter se exposto (...) e tem aquele outro paciente que vem sem dizer $\mathrm{A}$ nem B, que vem referindo "ah, pois é, eu tô com uma dor na ponta do dedo do pé" e dói, e investiga.... chega no final da consulta e ele diz assim "doutor, sabe o que é, eu queria ver se não dava pra pedir, já queria fazer uma avaliação de saúde, ver se ta tudo bem, será que não dá pra solicitar o exame?”. (...) Aí a gente entende o dedão do pé dele (prof.1).

\section{Ações de prevenção}

Segundo os relatos da equipe, as ações de prevenção ao HIV ocorrem nas consultas para coleta de citopatológico (CP), grupos de planejamento familiar, palestras na escola localizada no bairro, atividades durante a semana e o dia mundial contra a Aids: "dentro do planejamento familiar a gente nota que tem essa preocupação assim, quando se fala no preservativo, a gente não fala só por causa da gravidez" (prof.06). A temática da sexualidade e prevenção ao HIV-Aids basicamente não é abordada em outros grupos/ações (de terceira idade, de caminhada, de hipertensos e diabéticos) e em relação ao público masculino - este último, pouco presente nas ações da ESF. Segundo relatado por um profissional, "A gente atende muito mais mulher em geral do que os homens. São muito poucos homens. Se tiver dez consultas de manhã, por exemplo, um vai ser homem e nove serão mulheres" (profissional 3). A pouca presença de homens em serviços de saúde é observada em diversos serviços de saúde no Brasil, constituindo um fator de vulnerabilidade deste público (Guerriero, Ayres, Hearst, 2002). 
Além do trabalho preventivo realizado na unidade de saúde, os profissionais também relataram um trabalho preventivo na escola, caracterizado por palestras realizadas nas turmas, todos os anos. "Na escola também o pessoal faz palestra com os jovens, de doenças. Não só HIV, mas todas as doenças sexualmente transmissíveis" (prof.07). A palavra "palestra" foi usada pelos entrevistados para designar o trabalho realizado na escola, denotando um entendimento do HIV como um assunto sobre o qual deve-se "informar" e "ensinar", assim como qualquer outra doença. Dessa maneira, aborda-se o evento biológico Aids, mas não necessariamente o fenômeno social complexo que a constitui, negligenciando-se as peculiaridades simbólicas da transmissão sexual. Estudos têm apontado a necessidade de ações preventivas que envolvam diferentes perspectivas de educação em saúde, para além da abordagem estritamente informativa (Meyer et al, 2006; Paiva, 2000). "As epidemias, especialmente a de Aids, têm nos ensinado que a prevenção não deve ser reduzida a campanhas de massa, distribuição de materiais educativos e veiculação de informações qualificadas" (Brasil, 2001, p.33). A crítica não é direcionada a abordagem informativa em si - já que a informação também tem seu papel na educação em saúde - mas a sua abordagem prescritiva e ao fato de ela muitas vezes se constituir como a única alternativa nos serviços de saúde (Meyer et al, 2006). Seffner (1998) afirma que a estratégia mais eficiente é associar a Aids com o lúdico, o prazer, e a partir daí internalizar uma cultura de prevenção e cuidado. A abordagem preventiva centrada na relação sexualidade-doença muitas vezes impede que os adolescentes se reconheçam em situações de vulnerabilidade. Paiva (2010) afirma que quando as pessoas são infectadas pelo HIV, elas não pensam que estão se encontrando para isso, mas sim fazendo outras coisas em contextos bem específicos: amando, sentindo prazer ou dor, "resolvendo o assunto pra dormir logo e o marido deixar em paz", "ganhando o pão de cada dia", sendo homens e mulheres. É a partir dos contextos e cenas cotidianas e singulares que a prevenção deve ser pensada e efetivada.

\section{Dispensação de preservativos}

Outro aspecto a ser destacado diz respeito à percepção da equipe de que a presença da unidade facilita o acesso a preservativos. A dispensação é realizada na recepção da unidade, quando os usuários solicitam. Três dos sete ACS relataram 
levar preservativos nos bolsos e distribuir durante a realização de Visitas Domiciliares (VD), visando facilitar o acesso às pessoas que não costumam freqüentar a unidade de saúde. Tal aspecto é considerado positivo por Fernandes et al (2004), que apontam que "a busca do preservativo na unidade de saúde, ao contrário da distribuição via Agente Comunitário de Saúde, pode quebrar o caráter confidencial desta necessidade de muitos de nossos usuários” (2004, p.147).

\section{(Des)conexões com a rede assistencial}

Em relação aos fluxos de testagem e encaminhamento, as diretrizes para a atenção em HIV-Aids na atenção básica têm como perspectiva a integralidade das ações, preconizando-se a existência de uma rede de serviços integrada para o encaminhamento dos casos que não competem à atenção básica (Brasil, 2006b). Mesmo quando ocorre o encaminhamento para serviços especializados, é preconizada a realização de acompanhamento conjunto dos casos (co-responsabilidade) (Brasil, 2008).

Entretanto, as equipes investigadas nesse estudo não relataram nenhuma aproximação nesse sentido. Foi relatada a inexistência de comunicação formal ou informal com outros serviços, denotando um perfil de fragmentação da atenção. "Cada serviço faz sozinho. O paciente ta aqui, ele ta aqui. Quando ele vai lá pro Parque Belém, ou pro Vila Nova, ou Vila dos Comerciários ele ta lá. E essa comunicação ela é meio que difícil" (prof.3). Há pouca clareza em relação às formas de acesso aos serviços especializados. A maioria dos entrevistados, por exemplo, não sabia que os CTAs em Porto Alegre têm acesso por livre-demanda, não sendo necessária a guia de referência e contra-referência. Os entrevistados também relataram pouca visibilidade em relação ao que se constitui como política municipal em HIV-Aids, que na percepção deles se resume à distribuição de material informativo em épocas de campanhas, como no carnaval e no dia mundial da Aids. Isto aponta uma desarticulação do nível da gestão da política de Aids no município em relação a política e as equipes de atenção básica.

A unidade de ESF investigada tem como principal local de encaminhamento para a realização do exame anti-HIV um laboratório particular conveniado com a Secretaria Municipal de Saúde. Segundo relato de um profissional da equipe, o laboratório faz apenas o exame de triagem (ELISA). Quando o resultado é HIV- (não reagente), o laboratório entrega o resultado para o usuário em um envelope lacrado e 
solicita que o mesmo retorne para a unidade, para abertura do envelope junto ao médico. No entanto, os profissionais relatam que poucos usuários retornam à unidade, possivelmente por abrirem $\mathrm{o}$ envelope e interpretarem o resultado sem a consulta à equipe de ESF. Quando o resultado é HIV+ (reagente), o laboratório encaminha o usuário para um CTA, onde é realizado o aconselhamento e uma nova coleta de sangue para ser submetida a testagem anti-HIV. Dessa maneira, mesmo quando a solicitação do exame foi realizada pelos profissionais da ESF, o resultado HIV+ será entregue no CTA, que realizará o encaminhamento para o SAE. Ao invés de uma co-responsabilização ou trabalho integrado entre os serviços, como preconizado, ocorre uma fragmentação da atenção. Outro ponto de fragmentação ocorre em relação à entrega do resultado do exame anti-HIV e a prática do aconselhamento pós-teste. Sendo o exame realizado em um laboratório conveniado, sua responsabilidade é apenas a de executar e entregar o resultado do exame. O aconselhamento pós-teste, ao invés de ocorrer concomitantemente à entrega do exame, conforme preconizado na prática dos Centros de Testagem e Aconselhamento, só ocorre em um momento posterior, se o usuário procurar o serviço para o qual foi encaminhado.

\section{Discussão}

Algumas ações relatadas por integrantes da equipe nos levaram a problematizar os modos como determinados conceitos instrumentalizam as ações desenvolvidas. O exercício da problematização consiste em interrogar algo que aparece como naturalizado. Busca evidenciar os saberes que sustentam determinada prática, assim como seus efeitos. Além de desconstruir - através do exercício interrogativo - a problematização possibilita também a abertura para a constituição de novos saberes e práticas. Deve-se ressaltar que, apesar de se apoiar em falas dos participantes da pesquisa, a problematização não remete a uma individualização daquilo a que ela vem a interrogar. Tais falas são compreendidas como expressões de práticas sociais, apoiadas em saberes que informam tais práticas, mesmo que tenhamos nos "esquecido" ou nunca tenhamos interrogado quais são esses saberes.

Em relação aos critérios utilizados para a solicitação do teste anti-HIV, chama a atenção o que é considerado, pelos profissionais, como "histórico da pessoa". O chamado "histórico" está associado a fatores como: "ter múltiplos parceiros", "promiscuidade", morar em área de risco, uso de drogas. Não foi relatada a prática 
sexual sem preservativo, em si, como risco. Mas sim determinados comportamentos e características, como demonstram as falas a seguir: "Nessa região, talvez por causa dessas duas coisas assim, dessa característica, desse perfil da comunidade e também essa coisa do uso de drogas, que também a promiscuidade acaba rolando mais solta (prof.3)"; "Em relação à história, o caso clínico ali, está vendo emagrecimento, aqueles sintomas... usuário de drogas, pessoas que tem múltiplos parceiros, que a gente sabe, porque elas não dizem. Muitas vezes as Agentes vêm e trazem pra nós (prof.4)".

Os profissionais definem que "área de risco" é o chamado "beco", uma área de ocupação na região, com presença de tráfico e uso de drogas, carência social e econômica, sendo considerado que "quanto mais pobre, mais a doença rola" (prof.14). Também apareceu uma associação entre o risco de infecção pelo HIV e o público adolescente, sob o argumento de que eles "não dão bola pra informação" (prof.12).

A associação entre HIV e promiscuidade explicitada nas falas de alguns profissionais evidencia resquícios da constituição social da Aids como doença ligada ao excesso ou a contravenção e ao desvio (Seffner, 1998). Dessa maneira, a estigmatização da Aids se reflete no modo como ocorre a oferta das ações de prevenção e do teste antiHIV: não para a população geral, mas para públicos específicos e estigmatizados.

Segundo Souza e Czersnia (2010) “Ainda hoje, após 30 anos do surgimento da Aids, permanece o discurso de grupos de risco, comumente associado aos profissionais do sexo, às pessoas com multiplicidade de parceiros sexuais, aos usuários de drogas e às pessoas doentes que necessitam de transfusões de sangue" (p. 444). Ao investigarem as expectativas e demandas de usuários que acessam um Centro de Testagem e Aconselhamento, Souza e Czersnia (2010) constataram a permanência do imaginário que associa a Aids aos chamados "grupos de risco". Esse resultado vai ao encontro de nosso estudo, em que as pessoas com parceria aparentemente estável não são percebidas como vulneráveis, nem demandantes de estratégias de prevenção ou realização do teste anti-HIV. A diferença, no entanto, é que aquele estudo investigou a perspectiva de usuários, enquanto o nosso estudo investigou a perspectiva de profissionais de uma equipe de ESF. A existência de um imaginário comum evidencia $\mathrm{O}$ atravessamento moral das práticas em saúde, assim como a necessidade de educação permanente e incorporação de outros saberes às práticas em saúde, 
diversificando o repertório de respostas das equipes.

Outro relato também suscitou nossa análise acerca das noções que instrumentalizam o olhar dos profissionais para as ações de prevenção à Aids. Entre os sete ACS participantes da pesquisa, três relataram carregar preservativos nos bolsos e distribuí-los durante as visitas, visando facilitar o acesso de determinados segmentos populacionais que têm maior resistência em acessar a unidade de saúde. Os outros ACS não carregam preservativos, alegando atuarem em regiões onde residem moradores com "outro perfil", caracterizado por casais heterossexuais, aposentados, com melhores condições econômicas e sociais.

A divisão estabelecida em torno dos perfis dos moradores, determinando a quem se dirige ou não a intervenção, parece estar mais atrelada à noção de grupos de risco do que de vulnerabilidade.

Ao trabalhar implicitamente com a noção de grupos de risco, as equipes conformam uma divisão: aqueles que tem risco de se infectar ou a outras pessoas, aos quais são direcionadas ações; e aqueles que não apresentam risco, aos quais não são direcionadas ações. A noção de grupos de risco opera criando homogeneidades, a partir de certas características: renda, estado civil, condições sociais, orientação sexual. Ao mesmo tempo, não ter alguma dessas características implica estar "fora do risco" - o que fica evidente quando alguns ACS distribuem preservativos, enquanto outros não. A delimitação dos grupos de risco também segue critérios morais e moralizantes, como "promiscuidade", relatada por alguns profissionais anteriormente.

O trabalho com a noção de vulnerabilidade opera de modo distinto. Sendo ela uma noção multidimensional dimensões social, institucional e individual - uma dimensão não exclui nem sobredetermina a outra. Ou seja, uma pessoa pode estar em vulnerabilidade social (estar em situação de rua ou morar "no beco", por ex.), mas criar condições institucionais (acesso a serviço de saúde) e individuais que diminuam seu grau de vulnerabilidade à infecção pelo HIV. Da mesma maneira, outra pessoa pode não estar em vulnerabilidade social nem institucional, mas ter uma crença de que "escolhe bem as mulheres, só 'as de família"” e por isso não precisa usar preservativo, aspecto que a tornaria vulnerável no nível individual. Portanto, não é o fator "ser pobre" em si, "ser morador de rua" em si ou "ser adolescente" em si que determina o risco de infecção pelo HIV, mas o resultado 
final da interação entre as diferentes dimensões da vulnerabilidade.

A noção de grupos de risco, enquanto instrumento que guia uma forma de intervenção, opera por divisões e separações: "está em risco X não está em risco", os "perigosos" e as "vítimas". Já a noção de vulnerabilidade atua auxiliando na compreensão de diferentes modos de expressão da vulnerabilidade, demandando intervenções diferentes para cada uma delas. O fato da equipe não pensar sobre o risco de infecção pelo HIV entre casais aparentemente heterossexuais e estáveis acima de 50 anos, não direcionando ações, é justamente um fator que aumenta a vulnerabilidade de tal público. O pouco acesso de homens à unidade de saúde também pode expressar um fator de vulnerabilidade, do ponto de vista institucional, pois as intervenções depositam na mulher o papel de responsabilização pela prevenção, negligenciando as questões de gênero, relações desiguais de poder e assim por diante.

Um dos maiores problemas da intervenção pautada na noção de grupos de risco não é necessariamente privilegiar determinado grupo para as ações. Levando-se em consideração o conceito de equidade, presente no Sistema Único de Saúde, compreende-se que públicos em situação de vulnerabilidade social devem ter prioridade nas ações em saúde em comparação com outros públicos. No entanto, o risco está na estigmatização destes públicos e na criação do imaginário de que outros grupos/pessoas estariam protegidos. Ao invés disso, sugerimos que diferentes grupos/pessoas possam estar sujeitos a diferentes formas de intervenção, adequadas a cada contexto e formas de expressão da vulnerabilidade. Enquanto a noção de "grupos de risco" opera por uma lógica de exclusão - dentro/fora do grupo, com/sem risco - a vulnerabilidade opera por inclusão e multiplicidade. Ou seja, compreende a existência de diferentes formas de estar em vulnerabilidade e diferentes formas de intervir com cada público. Trata-se de substituir a lógica binária “ou, ou" pela lógica inclusiva e múltipla “e, e" (Deleuze, 1992).

Nesta perspectiva, sugerimos que os profissionais possam interrogar que dimensões da vulnerabilidade podem estar presentes em qualquer sujeito/grupo social, propiciando a universalização e singularização das intervenções. A universalização implica no direito ao acesso à prevenção para qualquer sujeito. Já a singularização implica em formas diferenciadas de prevenção e/ou acompanhamento, adequadas a cada contexto social, grupo e/ou indivíduo. 


\section{Considerações Finais}

Consideramos que a proposta política da ESF a constitui como um âmbito importante e estratégico para o desenvolvimento de ações de atenção no campo das DST/HIV-Aids. Porém, os dados apresentados demonstram que as ações de atenção em HIV-Aids ainda são incipientes.

A ESF representa uma possibilidade de expansão das ações, principalmente de prevenção ao HIV. Porém, tal expansão não vem sendo acompanhada da necessária discussão e qualificação das ações. Apontamos os riscos de banalização e medicalização do problema em questão. A banalização é caracterizada pela abordagem da Aids como qualquer outro problema de saúde, desconsiderando-se as especificidades da dimensão da sexualidade e relações de gênero. Já a medicalização é caracterizada pela abordagem eminentemente de cunho biomédico da Aids, negligenciando as dimensões sociais, psicológicas e políticas que marcam tal fenômeno. Uma das expressões desse processo é o direcionamento de ações de caráter eminentemente prescritivo-informativo. Apesar de ser uma modalidade preventiva, propiciando o aumento do acesso à informação, a estratégia preventiva baseada apenas em palestras apresenta limitações. Tal estratégia assenta-se na premissa de que a informação qualificada garante a prevenção, quando na verdade a prevenção é determinada por vários fatores, envolvendo aspectos afetivos, relações de gênero, as desigualdades de poder, os significados atribuídos ao sexo e a sexualidade. Nesse sentido, abordar a Aids como fenômeno complexo requer intervenções que possam abarcar estes outros aspectos. Ao problematizar a perspectiva estritamente biomédica presente na ESF, não devemos culpabilizar os profissionais que operam através dela, mas interrogar as condições que permitem a manutenção ou a quebra desta lógica, como a (in)existência de processos de educação permanente, falta de articulação, co-responsabilização e matriciamento entre os serviços de atenção básica e serviços especializados.

Da mesma maneira, evidenciamos o quanto a abordagem baseada na noção de grupos de risco continua atravessando de modo marcante as práticas em saúde. Como apontado por Ayres et al (2009a), as análises de risco podem ainda continuar sendo utilizadas, mas sempre de maneira contextualizada, incluindo os diversos fatores de variabilidade que compõem um fenômeno social considerado em sua complexidade. Nesse sentido, apontamos o 
desafio de que a descentralização de ações em HIV-Aids para a Estratégia Saúde da Família seja acompanhada por processos de qualificação da atenção em saúde, baseadas nas noções de vulnerabilidade, integralidade e co-responsabilidade das ações.

\section{$\overline{\text { Notas }}$}

${ }^{1} \mathrm{O}$ projeto foi aprovado pelo Comitê de Ética da Escola de Saúde Pública do RS (processo 432_08) e pelo Comitê de Ética da Secretaria Municipal de Saúde de Porto Alegre (processo 001.024953.09.1).

${ }^{2}$ Utilizamos este dado referente ao ano de 2006 pois foi a única publicação encontrada que discriminava a incidência segundo gerências distritais e unidades de saúde.

3 Os últimos boletins epidemiológicos divulgados pelo Ministério da Saúde tem levado em consideração a soma de pelo menos três sistemas de informação para chegar à taxa de incidência de Aids.

\section{Referências:}

Abdala, F.T.de M.., Nichiata, L.Y. I. (2008). A abertura de privacidade e o sigilo das informações sobre o HIV/Aids das mulheres atendidas pelo Programa Saúde da Família no
Município de São Paulo, Brasil. Revista Saúde e Sociedade, 17(2), p. 140-152.

Ayres, J.R, Calazans, G.J., Saletti Filho, H.C., França Júnior, I. (2009a). O conceito de vulnerabilidade $\mathrm{e}$ as práticas de saúde: novas perspectivas e desafios.. Em D Czeresnia, C. M. de Freitas. (Orgs.). Promoção da saúde: conceitos, reflexões, tendências (pp. 117 - 140). $2^{\mathrm{a}}$ ed. rev. e ampliada. Rio de Janeiro: Editora FIOCRUZ.

Ayres, J.R, Calazans, G.J., Saletti Filho, H.C., França Júnior, I. (2009b). Risco, vulnerabilidade e práticas de prevenção e promoção da saúde. Em G.W.S Campos e cols. (Org.). Tratado de Saúde Coletiva (pp. 375 418). São Paulo: HUCITEC.

Birman, J. A physis da saúde coletiva. PHYSIS: Rev. Saúde Coletiva, Rio de Janeiro, 15(Suplemento):11-16, 2005. p. $11-16$.

Brasil. (2012). Boletim epidemiológico AIDS - DST, VIII (01).

Brasil (2008). Centros de Testagem e Aconselhamento do Brasil: desafios para a equidade e o acesso. Brasília: Ministério da Saúde.

Brasil. (2006a). Portaria $n^{\circ}$ 648, de 28 de março de 2006. Aprova a Política Nacional de Atenção Básica, 
estabelecendo a revisão de diretrizes e normas para a organização da Atenção Básica para o PSF e o PACS. 2006a. Disponível em: <http://dtr2001.saude.gov.br/sas/PO RTARIAS/Port2006/GM/GM648.htm>. Acesso em: 02 jun. 2010.

Brasil. (2006b). HIV/Aids, hepatites e outras DST / Cadernos de Atenção Básica $n^{\circ} 18$ (Série A. Normas e Manuais Técnicos). Brasília : Ministério da Saúde.

Brasil (2005). Oficina de Aconselhamento em DST/HIV/AIDS para a atenção básica. Brasília: Ministério da Saúde.

Brasil. (2003). Aconselhamento em DST/HIV/Aids para a Atenção Básica. Brasília: Ministério da Saúde.

Brasil. (2001). Manual de Redução de Danos. Brasília: Ministério da Saúde. Deleuze, G. (1992). Conversações. Rio de Janeiro: Ed. 34.

Fernandes, M.E.L.F. e cols (Orgs.). (2004). Aids: prevenção porta a porta: construindo histórias de prevenção ao HIV/AIDS no Programa Saúde da Família na cidade de São Paulo. São Paulo, Associação Saúde da Família: Ed. HUCITEC.

Ferreira, F.C.; Nichiata, L.Y.I. (2008). Mulheres vivendo com aids e os profissionais do Programa Saúde da
Família: revelando o diagnóstico. Revista da escola de enfermagem/ USP, 42(3), 483 - 489.

Feuerweker, L. (2005).Modelos tecnoassistenciais, gestão e organização do trabalho em saúde: nada é indiferente no processo de luta para a consolidação do SUS. Interface - Comunicação, Saúde, Educação, 9(18), 489-506.

Franco, T.B.; Merhy, E.E.(2004). Programa de Saúde da Família (PSF): Contradições de um programa destinado à mudança do modelo tecnoassistencial. Em E.E. Merhy e cols. (Orgs.). O trabalho em saúde olhando e experienciando o SUS no cotidiano (pp. 55-124). $2^{\mathrm{a}}$ ed. São Paulo: Ed. Hucitec.

Gomes, R. (2007). Análise e interpretação de dados de pesquisa qualitativa. Em M.C.S Minayo (Org.). Pesquisa social: teoria, método e criatividade (pp. 79-108). 25 ed. Petrópolis, RJ: Ed. Vozes.

Guerriero, I; Ayres, J.R.C.M.; Hearst, N. (2002). Masculinidade e vulnerabilidade ao HIV de homens heterossexuais. Revista de Saúde Pública, 36(4), 50-60.

Herzlich, C.; Pierret, J. (2005). Uma doença no espaço público: a AIDS 
em seis jornais franceses. Physis, 15 (suppl), 71-101.

Meyer, D.E.E.; Mello, D.F.; Valadão, M.M.; Ayres, J.R.C.M. (2006) "Você aprende. A gente ensina?": interrogando relações entre educação e saúde desde a perspectiva da vulnerabilidade. Cadernos de Saúde Pública, 22 (6), 1335-1342.

Minayo, M.C.S. (1992). O desafio do conhecimento: Pesquisa Qualitativa em Saúde. São Paulo - Rio de Janeiro: Hucitec.

Paiva, V. (2000). Fazendo arte com a camisinha - sexualidades jovens em tempos de Aids. São Paulo: Summus.

Paiva, V. (2010). Viver a prevenção: contribuições dos referenciais dos direitos humanos para o campo das práticas. Conferência proferida no VIII Congresso Brasileiro de prevenção das DST e Aids. Brasília, $16-19$ junho.

Revel, J. (2005). Michel Foucault: conceitos essenciais. São Carlos: Claraluz, 2005.

Seffner, F. (1998). O conceito de vulnerabilidade: uma ferramenta útil em seu consultório. Aletheia, 7(1), 53-58.

Silva, L.M.S.; Guimarães, T.A.; Pereira, M.S.D.; Miranda, K.C.L.; Oliveira, E.M. (2005). Integralidade em saúde: avaliando a articulação e a coresponsabilidade entre o Programa Saúde da Família e um serviço de referência em HIV/aids. Epidemiologia e Serviços de Saúde, 14(2), 97-104.

Seoane, A.F.; Fortes, P.A.C. (2009). A Percepção do Usuário do Programa Saúde da Família sobre a Privacidade e a Confidencialidade de suas Informações. Revista Saúde e Sociedade, 18(1), .42 - 49.

SMS-POA. (2008). Secretaria Municipal de Saúde de Porto Alegre. Boletim Epidemiológico, X(36).

Sousa, M.C.P.; Santo, A.C.G.E.; Motta, S.K.A. (2008). Gênero, vulnerabilidade das mulheres ao HIV/Aids e ações de prevenção em bairro da Periferia de Teresina, Piauí, Brasil. Revista Saúde e Sociedade, 17(2), 58-68.

Souza, V.S; Czersnia, D. (2010). Demandas e expectativas de usuários de centro de testagem e aconselhamento anti-HIV. Revista de Saúde Pública, 44(3), 441-447.

Gustavo Zambenedetti: Professor do Departamento de Psicologia da Universidade Estadual do Centro-Oeste (UNICENTRO) - Campus Irati-PR. Doutorando do Programa de PósGraduação em Psicologia Social e 
Institucional - Universidade Federal do Rio Grande do Sul (UFRGS). Endereço: Rua Frei Orlando, n. 52, ap. 41. Centro. Irati/PR. CEP: 84500-000. Telefone: 42 99853889.

E-mail: gugazam@yahoo.com.br

Nalu Silvana Both: Centro de Testagem e Aconselhamento do Ambulatório de Dermatologia Sanitária (CTA/ADS) / Secretaria de Estado da Saúde do Rio Grande do Sul. É formada em Psicologia pela PUC-RS. Mestre em Sociologia (UFRGS).

E-mail: naluboth@gmail.com 